\title{
Editorial: Aegilops: Promising Genesources to Improve Agronomical and Quality Traits of Wheat
}

\author{
Marianna Rakszegi ${ }^{1 *}$, István Molnár ${ }^{1}$, Éva Darkó ${ }^{1}$, Vijay K. Tiwari ${ }^{2}$ and Peter Shewry ${ }^{3}$ \\ ${ }_{1}^{1}$ Agricultural Institute, Centre for Agricultural Research, Martonvásár, Hungary, 2 Plant Science and Ladscape Architecture, \\ University of Maryland, Washington, MD, United States, ${ }^{3}$ Department of Plant Science, Rothamsted Research, Harpenden, \\ United Kingdom
}

Keywords: Aegilops sp., stress tolerance, quality traits, genome analysis, alien introgression

Editorial on the Research Topic

Aegilops: Promising Genesources to Improve Agronomical and Quality Traits of Wheat

\section{INTRODUCTION OF AEGILOPS}

Aegilops species have contributed significantly to wheat improvement despite the challenges in exploiting wild species, such as crossability and incompatibility (Börner et al., 2015; Fedak, 2015). They have been used in particular as sources of genes conferring resistance to biotic stresses, but also for more complex traits such as abiotic stress and yield.

The genus Aegilops consists of 22 species with the C, D, M, N, S, T and U genomes, which have high allelic diversity relative to wheat. Aegilops tauschii, the D-genome donor of bread wheat, has been most widely used for wheat breeding, followed by $A$. speltoides and A. ventricosa. However, because most Aegilops species are in the secondary and tertiary gene pools of wheat they are difficult to utilize due to recombination barriers and useful variation from these species is only available in the form of translocation/introgression lines.

\section{IDENTIFICATION OF DIVERSITY IN TRAITS FOR WHEAT IMPROVEMENT}

As sources of tolerance to biotic stresses, $20 \%$ of the total number (over 75) resistance gene loci identified in cereals are present in Aegilops species (Ponce-Molina et al., 2018). These include two thirds of the 54 loci for resistance to powdery mildew (Tang et al., 2018), and the 12 resistance loci for Cereal Cyst Nematodes (Ali et al., 2019). In the present topic, the addition of A.markgrafii chromosomes to wheat increased the resistance to 19 of 20 powdery mildew isolates in addition line $\mathrm{AV}(\mathrm{E})$ (Niu et al.).

New stem rust resistance genes have also been identified in Aegilops, such as Sr46, Sr47, Sr51 and Sr53 (in A. tauschii, A. triuncialis, A. searsii and A. geniculata respectively; Liu et al., 2011a; Liu et al., 2011b; Klindworth et al., 2012; Yu et al., 2015) and three additional genes in A. tauschii (Rouse et al., 2011), three genes in Ae. sharonensis (Singh et al., 2015; Yu et al., 2017) and one gene in $A$. umbellulata (Edae et al., 2016). In addition, it has been reported that $81 \%$ of accessions of $A$. 
longissima, $94 \%$ of $A$. neglecta and $88 \%$ of A. cylindrica (DDCC) and $A$. peregrina (SSUU) were resistant to the Ug99 race group of the stem rust pathogen (Puccinia graminis f. sp. tritici) (Huang et al., 2018; Olivera et al., 2018) (Kishii). In this topic Niu et al. reported that wheat/A.markgrafii addition lines AII(C) and AIII (D) were resistant to Ug99. Furthermore, A. biuncialis, A. caudata, A. comosa, A. cylindrica, A. geniculata, A. neglecta, A. peregrina, A. triuncialis, and A. umbellulata were evaluated for resistance to three highly virulent races (TTKSK, TRTTF and TTTTF) of $P$. graminis f. sp. tritici with $60-70 \%$ exhibiting low infection types. Association analyses showed that for a given species, the resistance genes are effective against multiple races (Olivera et al., 2018).

Brisco et al. (2017) identified several A. tauschii accessions showing resistance to Fusarium Head Blight and studies reported in this topic (Szabo-Hever et al.) have shown that A. tauschii accessions decreased disease severities by $18.3 \%$, suggesting that either the D genome or the increased ploidy level could contribute to resistance in synthetic hexaploid lines.

Aegilops species are also a resource for novel genes and alleles providing tolerance to abiotic stresses. In this topic Suneja et al. provide a good example of the identification of several A. tauschii accessions as potential donors of adaptive plasticity to stress.

Aegilops species also serve as a resource for introducing useful genetic variation in grain processing and nutritional quality in wheat (Triticum aestivum). Seed storage proteins are the major determinants of end product quality and mainly consist of glutenins and gliadins. A large number of allelic forms of these proteins have been identified in Aegilops species and in some Aegilops species such as $A$. searsii, A. geniculata and $A$. longissima this variation have been linked with improved breadmaking quality. Aegilops species has also been explored for diversity in the grain texture-related proteins, called puroindolins (Pins) and grain softness proteins (GSP). In particular, studies carried out in a number of countries have identified almost 100 alleles of Pin $a$, Pin $b$ and GSP across 200 lines/accessions. This allelic variation could be utilized in breeding programs to extend the textural characteristics of wheat (Kumar et al.).

Aegilops has attracted further attention in relation to increasing the grain mineral content of wheat. In particular, to produce biofortified wheat with higher the contents of iron and zinc in order to alleviate deficiencies in these minerals which currently affect more than 2 billion people worldwide (Cakmak, 2017; Black et al., 2013; Velu et al., 2018b). Some Aegilops species have been reported to contain three to four-fold higher concentrations of $\mathrm{Zn}$ and $\mathrm{Fe}$ grain content than wheat, including A. longissima (Sl), A. kotschyi (US), A. peregrina (US), A. cylindrica (CD), A. ventricosa (DN) and A. geniculata (UM) (Rawat et al., 2009). Amphiploid lines of durum wheat with A. longissima, partial amphiploids of bread wheat with $A e$. kotschyi and addition/substitution lines of bread wheat with $A$. kotschyi also showed two to three times higher concentrations of $\mathrm{Zn}$ and $\mathrm{Fe}$ in grain than the wheat checks (Tiwari et al., 2008; Tiwari et al., 2010; Rawat et al., 2011), indicating that they are promising resources to improve wheat composition. Velu et al. developed translocation lines with rye and different Aegilops species in a wheat genetic background to increase the $\mathrm{Zn}$ content. Although the potential health benefits of Aegilops species by increased minerals in wheat have not yet been realized, they should have an impact in the future (Kishii).

\section{ESTABLISHMENT AND EXPLOITATION OF GENOMIC RESOURCES IN AEGILOPS SPP.}

A high-throughput genotyping platform has been specifically designed for screening species related to wheat and used to screen multiple accessions representing all species in the genus Aegilops. This application was useful for identifying diversity and determining the relationships within and between Aegilops species (Przewieslik-Allen et al.). Genome adaptability to environmental changes, especially to rapid climatic fluctuations, underlies the survival and evolution of species. In wild species, genetic and epigenetic changes are accompanied by significant alterations in the complex nuclear repetitive DNA fraction. Perpetual intraorganismal reshuffling of repetitive DNA mirrors the structural plasticity of the A. speltoides genome, which is related to genetic diversity through the distribution of the species in contrasting ecogeographical environments (Pollak et al.). Ruban and Badaeva proposed a model for the evolution of the S-genome of $A$. speltoides. The genomes of allopolyploid wheats have evolved by different species-specific chromosome translocations, sequence amplification, and elimination and re-patterning of repetitive DNA sequences. These events occurred independently in different wheat species and in A. speltoides. The $5 \mathrm{~S}$ rDNA locus of chromosome $1 \mathrm{~S}$ was probably lost in ancient $A$. speltoides prior to formation of cultivated Triticum timopheevi (AAGG genomes), but after the emergence of ancient emmer (AABB genomes). rDNA profiling and distribution was used to divide diploid Aegilops species into two groups corresponding to the Emarginata and Truncata sub-sections. It was found that the evolution of Emarginata species was associated with an increase of C-banding and heterochromatin, amplification of Spelt-52, re-pattering of the pAesp_SAT86, and a gradual decrease in the amount of the $\mathrm{D}$-genome-specific repeats pAs1, pTa-535, and pTa-s53.

A. tauschii $(2 \mathrm{n}=2 \mathrm{x}=14$, genome $\mathrm{DD})$, also known as Tausch's goatgrass, is the $\mathrm{D}$ genome donor of hexaploid bread wheat ( $T$. aestivum, $2 \mathrm{n}=2 \mathrm{x}=42$, AABBDD genome). It is a rich source for tolerance to biotic and abiotic stresses. A TILLING (Targeting Induced Local Lesions In Genomes) population of $A$. tauschii (TILL-D) was developed using ethyl methanesulphonate (EMS) as a mutagen which, together with the newly published $A$. tauschii reference genome sequence, will facilitate the discovery and validation of genes for agronomically important traits and their transfer into bread wheat (Rawat et al.). Population structure analysis based on high quality SNPs confirmed the differentiation of A. tauschii into two lineages (L1 and L2). A MiniCore collection consisting of $29 \mathrm{~L} 1$ and $11 \mathrm{~L} 2$ accessions was identified based on genotypic, phenotypic and geographical 
data. This captures $84 \%$ of the total allelic diversity in the whole collection, showing that it is possible to reduce the number of accessions which need to be screened by $90 \%$ (Singh et al.). A genome wide association study (GWAS) of the grain $\mathrm{Fe}, \mathrm{Zn}, \mathrm{Cu}$ and $\mathrm{Mn}$ contents also indicated that A. tauschii lineage $2 \mathrm{had}$ higher $\mathrm{Fe}$ and $\mathrm{Cu}$ concentration than lineage 1 (Arora et al.). The associations were related to genes encoding transcription factor regulators, mineral transporters and phytosiderophore synthesis.

The stability of translocation or alien introgression lines is always of concern. King et al. developed homozygous wheat/A. muticum dihaploid introgression lines and characterized their stability using genomic in situ hybridization and SNP analysis (King et al.). Zhang et al. studied the efficiency of transferring $A$. tauschii segments to wheat using a synthetic octaploid (AABBDDDD, $2 \mathrm{n}=8 \mathrm{x}=56$ ) and used bridge crosses to mapped QTL for agronomically important traits.

Wheat/A. markgrafii disomic addition lines carrying the chromosomes B, C, D, E, F and G, respectively, were screened with SSR markers showing that they corresponded to wheat homoeologous groups 2, 5, 6, 7, 3, and 4, respectively. Useful markers were also identified for chromosome engineering of wheat (Niu et al.).

The papers brought together in this topic therefore illustrate the range of current research on the charcterisation of Aegilops

\section{REFERENCES}

Ali, M. A., Shahzadi, M., Zahoor, A., Dababat, A. A., Toktay, H., Bakhsh, A., et al. (2019). Resistance to cereal cyst nematodes in wheat and barley: an emphasis on classical and modern approaches. Int. J. Mol. Sci. 20, E432. doi: 10.3390/ ijms20020432

Börner, A., Ogbonnaya, F. C., Röder, M. S., Rasheed, A., Periyannan, S., and Lagudah, E. S. (2015). “Aegilops tauschii introgressions in wheat," in Alien Introgression in Wheat: Cytogenetics, Molecular Biology, and Genomics. Eds. M. Molnár-Láng, C. Ceoloni and J. Dolezel (London: Springer), p.245-p.272.

Black, R. E., Victora, C. G., Walker, S. P., Bhutta, Z. A., Christian, P., de Onis, M., et al. (2013). Maternal and child undernutrition and overweight in low-income and middle-income countries. Lancet 382, 427-451. doi: 10.1016/s0140-6736 (13)60937-x

Brisco, E. I., Brown, L. K., and Olson, E. L. (2017). Fusarium head blight resistance in Aegilops tauschii. Genet. Resour. Crop Evol. 64, 2049-2058. doi: 10.1007/ s10722-017-0495-3

Cakmak, I. (2007). Enrichment of cereal grains with zinc: agronomic or genetic biofortification? Plant Soil 302, 1-17. doi: 10.1007/s11104-007-9466-3

Edae, E. A., Olivera, P. D., Jin, Y., Poland, J. A., and Rouse, M. N. (2016). Genotype-by-sequencing facilitates genetic mapping of a stem rust resistance locus in Aegilops umbellulata, a wild relative of cultivated wheat. BMC Genomics 17, 1039. doi: 10.1186/s12864-016-3370-2

Fedak, G. (2015). "Alien introgressions from wild Triticum species, T. monococcum, T. urartu, T. turgidum, T. dicoccum, T. dicoccoides, T. carthlicum, T. araraticum, T. timopheevii, and T. miguschovae," in Alien Introgression in Wheat: Cytogenetics, Molecular Biology, and Genomics. Eds. M. Molnár-Láng, C. Ceoloni and J. Dolezel (London: Springer), p.191-p.219. doi: 10.1007/978-3-319-23494-6_8

Huang, S., Steffenson, B. J., Sela, H., and Stinebaugh, K. (2018). Resistance of Aegilops longissima to the rusts of wheat. Plant Dis. 102, 1124-1135. doi: 10.1094/PDIS-06-17-0880-RE

Klindworth, D. L., Niu, Z., Chao, S., Friesen, T. L., Jin, Y., Faris, J. D., et al. (2012). Introgression and characterization of a goatgrass gene for a high level of resistance to ug99 stem rust in tetraploid wheat. G3 2, 665-673. doi: 10.1534/ g3.112.002386 species and identification of important traits for exploitation in wheat improvement.

\section{AUTHOR CONTRIBUTIONS}

MR, PS, VT, ÉD, and IM wrote this manuscript.

\section{FUNDING}

The topic is based upon the workplan of the COST Action 18101 SOURDOMICS-Sourdough biotechnology network towards novel, healthier and sustainable food and bioprocesses, where the members of the working group 1 were supported by COST (European Cooperation in Science and Technology). COST is a funding agency for research and innovation networks.

\section{ACKNOWLEDGMENTS}

We are grateful to all authors that contributed to this e-book.

Liu, W., Jin, Y., Rouse, M., Friebe, B., Gill, B. S., and Pumphrey, M. O. (2011a). Development and characterization of wheat-Ae. searsii robertsonian translocations and a recombinant chromosome conferring resistance to stem rust. Theor. Appl. Genet. 122, 1537-1545. doi: 10.1007/s00122-011-1553-4

Liu, W., Rouse, M., Friebe, B., Jin, Y., Gill, B. S., and Pumphrey, M. O. (2011b). Discovery and molecular mapping of a new gene conferring resistance to stem rust, Sr53, derived from Aegilops geniculata and characterization of spontaneous translocation stocks with reduced alien chromatin. Chromosome Res. 19, 669-682. doi: 10.1007/s10577-011-9226-3

Olivera, P. D., Rouse, M. N., and Jin, Y. (2018). Identification of new sources of resistance to wheat stem rust in Aegilops spp. in the tertiary genepool of wheat. Front. Plant Sci. 9, 1719. doi: 10.3389/fpls.2018.01719

Ponce-Molina, L. J., Huerta-Espino, J., Singh, R. P., Basnet, B. R., Alvarado, G., Randhawa, M. S., et al. (2018). Characterization of leaf rust and stripe rust resistance in spring wheat 'Chilero'. Plant Dis. 102, 421-427. doi: 10.1094/ PDIS-11-16-1545-RE

Rawat, N., Tiwari, V. K., Singh, N., Randhawa, G. S., Singh, K., Chhuneja, P., et al. (2009). Evaluation and utilization of Aegilops and wild Triticum species for enhancing iron and zinc content in wheat. Genet. Resour. Crop Evol. 56, 53-64. doi: $10.1007 /$ s10722-008-9344-8

Rawat, N., Neelam, K., Tiwari, V. K., Randhawa, G. S., Friebe, B., Gill, B. S., et al. (2011). Development and molecular characterization of wheat-Aegilops kotschyi addition and substitution lines with high grain protein, iron, and zinc. Genome 54, 943-953. doi: 10.1139/g11-059

Rouse, M. N., Olson, E. L., Gill, B. S., Pumphrey, M. O., and Jin, Y. (2011). Stem rust resistance in Aegilops tauschii germplasm. Crop Sci. 51, 2074-2078. doi: 10.2135/cropsci2010.12.0719

Singh, R. P., Hodson, D. P., Jin, Y., Lagudah, E. S., Ayliffe, M. A., Bhavani, S., et al. (2015). Emergence and spread of new races of wheat stem rust fungus: continued threat to food security and prospects of genetic control. Phytopathology 105, 872-884. doi: 10.1094/PHYTO-01-15-0030-FI

Tang, S., Hu, Y., Zhong, S., and Luo, P. (2018). The potential role of powdery mildew-resistance gene Pm40 in Chinese wheat-breeding programs in the post-Pm21 Era. Engineering 4, 500-506. doi: 10.1016/j.eng.2018.06.004

Tiwari, V. K., Rawat, N., Neelam, K., Randhawa, G. S., Singh, K., Chhuneja, P., et al. (2008). Development of Triticum turgidum subsp. durum-Aegilops longissima amphiploids with high iron and zinc content through 
unreduced gamete formation in F1 hybrids. Genome 51, 757-766. doi: $10.1139 / \mathrm{G} 08-057$

Tiwari, V. K., Rawat, N., Neelam, K., Kumar, S., Randhawa, G. S., and Dhaliwal, H. S. (2010). Random chromosome elimination in synthetic Triticum-Aegilops amphiploids leads to development of a stable partial amphiploid with high grain micro- and macronutrient content and powdery mildew resistance. Genome 53, 1053-1065. doi: 10.1139/G10-083

Velu, G., Singh, R. P., Crespo-Herrera, L., Juliana, P., Dreisigacker, S., Valluru, R., et al. (2018b). Genetic dissection of grain zinc concentration in spring wheat for mainstreaming biofortification in CIMMYT wheat breeding. Sci. Rep. 8, 13526. doi: 10.1038/s41598-018-31951-z

Yu, G., Zhang, Q., Friesen, T. L., Rouse, M. N., Jin, Y., Zhong, S., et al. (2015). Identification and mapping of Sr46 from Aegilops tauschii accession CIae 25 conferring resistance to race TTKSK (Ug99) of wheat stem rust pathogen. Theor. Appl. Genet. 128, 431-443. doi: 10.1007/s00122-014$2442-4$
Yu, G., Champouret, N., Steuernagel, B., Olivera, P. D., Simmons, J., Williams, C., et al. (2017). Discovery and characterization of two new stem rust resistance genes in Aegilops sharonensis. Theor. Appl. Genet. 130, 1207-1222. doi: $10.1007 / \mathrm{s} 00122-017-2882-8$

Conflict of Interest: The authors declare that the research was conducted in the absence of any commercial or financial relationships that could be construed as a potential conflict of interest.

Copyright (c) 2020 Rakszegi, Molnár, Darkó, Tiwari and Shewry. This is an openaccess article distributed under the terms of the Creative Commons Attribution License (CC BY). The use, distribution or reproduction in other forums is permitted, provided the original author(s) and the copyright owner(s) are credited and that the original publication in this journal is cited, in accordance with accepted academic practice. No use, distribution or reproduction is permitted which does not comply with these terms. 